\title{
Endovascular Treatment for Low-Grade (Spetzler-Martin I-II) Brain Arteriovenous Malformations
}

\author{
(D) H. Baharvahdat, (DR. Blanc, (D) R. Fahed, (DS. Smajda, (D) G. Ciccio, (D).-P. Desilles, DH. Redjem, (DS. Escalard, (D) M. Mazighi, \\ (DD. Chauvet, (D)T. Robert, DP. Sasannejad, and (D) M. Piotin
}

\begin{abstract}
BACKGROUND AND PURPOSE: Surgical resection is usually considered as the first-line curative strategy for low-grade (Spetzler-Martin grade I-II) brain arteriovenous malformations because it has a high cure rate and low complications. The role of endovascular treatment remains to be clarified in this indication, especially after A Randomized Trial of Unruptured Brain Arteriovenous Malformations. Our objective was to assess the safety and efficacy of first-line endovascular treatment in low-grade brain arteriovenous malformation management at our institution.
\end{abstract}

MATERIALS AND METHODS: Patients with low-grade brain arteriovenous malformations treated primarily with embolization in our department between January 2005 and December 2015 were retrieved from our prospectively collected registry. The primary outcome was the brain arteriovenous malformation obliteration rate, and secondary outcomes were disability or death secondary to brain arteriovenous malformation embolization assessed through modification of the modified Rankin Scale.

RESULTS: Two hundred twenty-four patients completed endovascular treatment during the study period and represent our study population. Complete exclusion of brain arteriovenous malformations was achieved in 205 patients (92\%), including 62.1\% of brain arteriovenous malformation exclusions after a single endovascular treatment session. One patient died of a hemorrhagic complication after endovascular treatment, leading to a mortality rate of $0.4 \%$. Twelve patients (5\%) kept a permanent neurologic deficit secondary to a complication of the endovascular treatment. An overall good outcome (mRS 0-2) was reported in 179 patients $(80 \%)$.

CONCLUSIONS: Endovascular treatment might be a suitable alternative to surgical resection for complete exclusion of selected lowgrade brain arteriovenous malformations.

ABBREVIATIONS: $\mathrm{BAVM}=$ brain arteriovenous malformation; $\mathrm{EVT}=$ endovascular treatment

$\mathbf{S}$ urgery is considered the first-line treatment for low-grade (Spetzler-Martin grades I and II) brain arteriovenous malformations (BAVMs), with high cure rates (94\%-100\%) and low complications (0\%-6\%). ${ }^{1}$ After the publication of A Randomized Trial of Unruptured Brain Arteriovenous Malformations (ARUBA) results in favor of medical conservative management, ${ }^{2}$ multiple criticisms emerged. ${ }^{3}$ Notably, some authors suggested that the 3 -fold increase in death or stroke in the interventional group was

Received September 25, 2018; accepted after revision January 8, 2019.

From the Department of Interventional Neuroradiology (H.B., R.B., R.F., S.S., G.C., J.-P.D, H.R., S.E., M.M., P.S., M.P.) and Neurosurgical Department (D.C.), Rothschild Foundation, Paris, France; and Neurosurgical Department (T.R.), Ente-OspedalieroCantonale Ospedale Civico di Lugano, Lugano, Switzerland.

Clinical Study: Long Term Follow-up after Embolization of Brain Arteriovenous Malformations (MAV-endovasc), https://clinicaltrials.gov/ct2/show/NCT02879071.

Please address correspondence to Raphaël Blanc, MD, Department of Interventional Neuroradiology, Rothschild Foundation, 25 rue Manin, Paris, France; e-mail: rblanc@for.paris

http://dx.doi.org/10.3174/ajnr.A5988 at least partially due to the low rate of patients treated surgically and the preferable use of endovascular treatment (EVT). In ARUBA, low-grade BAVMs ${ }^{4}$ were also poorly represented (13\%). To assess the safety and efficacy of EVT of low-grade BAVMs, we reviewed our experience with low-grade cerebral BAVM management at Rothschild Foundation, Paris, where embolization is the first-line therapy.

\section{MATERIALS AND METHODS \\ Baseline Characteristics of Patients and BAVMs}

From our prospectively collected data base, we retrieved lowgrade BAVMs treated by an endovascular approach in our Interventional Neuroradiology Department between January 2005 and December 2015. Patients with low-grade BAVMs who completed all treatment procedures were enrolled in the study. We excluded the patients who had ongoing treatment or were lost during follow-up. Baseline clinical characteristics of patients were reviewed. Clinical status was assessed according to the modified Rankin Scale at the initial and follow-up visits. Cross-sectional imaging 
and angiograms were reviewed for precise BAVM location, size, and angioarchitecture and classification according to the Spetzler-Martin grade. BAVMs were classified as cortical, deep, or infratentorial. The anatomic grading was established by 2 senior operators independent of the endovascular treatments.

The study protocol was approved by the local ethics committee. According to the French regulations, the board waived the need for signed consent for patients included in the study.

\section{Endovascular Procedures}

Patients were allocated to treatment after multidisciplinary discussions involving interventional neuroradiologists (with a neurosurgical or a radiologic background) and at least 1 vascular neurosurgeon. During the investigation, EVT was the first choice for low-grade BAVMs with a curative goal (ie, complete obliteration of the nidus by an endovascular approach in 1 single session whenever possible).

EVTs were performed with the patient under general anesthesia. In the study period, Onyx (Covidien, Irvine, California) was the most commonly used agent for embolization of AVMs. Occasionally, $n$-butyl-2-cyanoacrylate (Histoacryl; Braun, Melsungen, Germany) or Glubran 2 (GEM, Viareggio, Italy) was injected during the procedure for high-flow fistulas. Only a transarterial approach was used. The procedure was stopped when complete occlusion was achieved or when there was a 2-cm reflux of Onyx in the nondetachable microcatheter or Onyx reflux to the proximal end of the detachable part in the detachable microcatheter. If necessary, multiple pedicles were embolized in 1 session to achieve the desired occlusion of the AVM. A head CT scan was performed in the operating room after each procedure or immediately if any perforation occurred. After the procedure, all patients were admitted to the intensive care unit with control of systolic blood pressure for 24-48 hours and were discharged within 4-5 days if there was no complication. Cerebral MR imaging was performed before and after the procedure for all patients. In case of multiple sessions, the interval between the 2 procedures was 1-4 months. Pre- and postprocedural complications were prospectively collected.

\section{Angiographic and Clinical Outcome}

All patients treated in our center systematically underwent a 6-month follow-up DSA after the last treatment session: BAVM occlusion, defined by a complete nidus occlusion with no residual arteriovenous shunt and no early venous filling, was assessed by an interventional neuroradiologist who was independent of the operators who performed the treatment.

Clinical assessment of the patient was performed by neurologists from the same center who were independent of the operators performing the endovascular treatments. Imaging evaluation was also performed by independent interventional neuroradiologists. Any new neurologic deficit was collected and considered as transient if it resolved within 1 month after endovascular treatment or as permanent if it remained for $>1$ month. The outcomes were classified as poor for mRS 3-6 and as good for mRS 0-2.

\section{Statistical Analysis}

Continuous data are presented as means \pm SDs, and categorical data , as count and percentage. Statistical comparisons were per- formed by a Student $t$ test for normally distributed data, the Mann-Whitney $U$ test for data with a skewed distribution, and the $\chi^{2}$ and Fisher exact tests for the categorical data. To assess the risk factors of poor outcome $(\mathrm{mRS}>2$ ), we performed univariate analysis using baseline characteristics of the patients, AVM angioarchitecture, and endovascular procedure variables. Multivariate analysis was performed to define independent predictive variables of poor outcome using binary logistic regression. A $P$ value $<.05$ was statistically significant. The data were analyzed using the Statistical Package for the Social Sciences (Version 16.0; IBM, Armonk, New York).

By increasing the time of the study and the number of patients, we attempted to reduce the bias effects related to the structural design of the study. Data, analytic methods, and study materials will be made available to any researcher for reproducing the results or replicating the procedure. Requests to receive these materials should be sent to the corresponding author, who will maintain their availability.

\section{RESULTS}

\section{Basic Characteristics of Patients}

From 2005 to 2015, a total of 330 patients with low-grade AVMs were managed in our hospital. Two hundred eighty-eight patients received EVT. Fifty-six patients who were still undergoing treatment during this period and 8 patients who were lost during follow-up were excluded from the study. These 8 patients did not experience any immediate complications after embolization. Two hundred twenty-four patients who completed EVT (ie, patients with AVM exclusion after EVT confirmed on 6-month follow-up angiography or patients with a remnant AVM but no residual access that would allow pursuing EVT) were included in the present study (baseline characteristics available in Table 1).

\section{Treatment Outcome}

The mean duration of angiographic follow-up after treatment was $9.7 \pm 11.9$ months. Complete exclusion of BAVMs was achieved in 205 patients (92\%). From 224 patients, 139 patients (62.1\%) were cured with a single endovascular procedure; $51(22.8 \%)$, with 2 procedures; $26(11.6 \%)$, with 3 procedures; and 8 (3.6\%), with $>3$ procedures. In 19 patients with incomplete AVM exclusion after EVT, treatment was completed with an operation in 8 patients $(3.6 \%)$ and radiosurgery in 9 patients $(4 \%)$. The 2 remaining patients underwent no further treatment. The complete exclusion rate did not differ among the cortical and subcortical BAVMs, deeply located BAVMs, or infratentorially located BAVMs (Table 2). Delayed hemorrhagic complications after EVT were encountered in 11 patients (5\%), and severe ischemic complication occurred in 5 patients (2\%). Thirty-two patients (14\%) developed a new neurologic deficit: Twenty patients (9\%) improved completely within 30 days of the operation, and 12 patients (5\%) kept a permanent deficit (7 patients [3\%] from hemorrhagic complications and 5 patients [2\%] from ischemic complications). An overall good outcome (mRS 0-2) was reported in 179 patients $(80 \%)$. Thirteen patients $(6 \%)$ had a worse mRS score compared with their preoperative status, including 9 patients $(69 \%)$ with a hemorrhagic presentation. The mortality rate was $0.4 \%$.

AJNR Am J Neuroradiol 40:668-72 Apr 2019 www.ajnr.org 
Table 1: Baseline characteristics and results of endovascular treatment ${ }^{a}$

\begin{tabular}{|c|c|c|c|c|}
\hline & $\begin{array}{c}\text { Total } \\
(n=224)\end{array}$ & $\begin{array}{c}\text { Ruptured } \\
\text { BAVMs } \\
(n=136)\end{array}$ & $\begin{array}{c}\text { Unruptured } \\
\text { BAVMs } \\
(n=88)\end{array}$ & $\begin{array}{c}P \\
\text { Value }\end{array}$ \\
\hline Age (yr) & $37.8 \pm 16$ & $37.9 \pm 17.7$ & $37.6 \pm 13.3$ & .087 \\
\hline Male & 127 (57\%) & $81(60 \%)$ & $46(52 \%)$ & .282 \\
\hline Presentation & & & & NA \\
\hline Hemorrhage & $136(60 \%)$ & $136(100 \%)$ & $0(0 \%)$ & \\
\hline Seizure & $42(19 \%)$ & $0(0 \%)$ & $42(48 \%)$ & \\
\hline Incidental & 37 (17\%) & $0(0 \%)$ & $37(42 \%)$ & \\
\hline Other & $9(4 \%)$ & $0(0 \%)$ & $9(10 \%)$ & \\
\hline Initial mRS score & & & & .0001 \\
\hline Good (0-2) & $178(79 \%)$ & $91(67 \%)$ & $87(99 \%)$ & \\
\hline Poor (3-5) & $46(21 \%)$ & $45(33 \%)$ & $1(1 \%)$ & \\
\hline BAVM location & & & & .001 \\
\hline Cortical and subcortical & $176(79 \%)$ & $96(71 \%)$ & $80(90 \%)$ & \\
\hline Deep & $19(8 \%)$ & 15 (11\%) & $4(5 \%)$ & \\
\hline Infratentorial & $29(13 \%)$ & 25 (18\%) & $4(5 \%)$ & \\
\hline Eloquent area & $77(34 \%)$ & $55(40 \%)$ & $22(25 \%)$ & .017 \\
\hline Spetzler-Martin grade & & & & .361 \\
\hline 1 & $71(32 \%)$ & $40(29 \%)$ & $31(35 \%)$ & \\
\hline II & $153(68 \%)$ & $96(71 \%)$ & $57(65 \%)$ & \\
\hline Mean nidus diameter $(\mathrm{cm})$ & $2.1 \pm 1.1$ & $1.9 \pm 1.1$ & $2.4 \pm 1.1$ & .0001 \\
\hline Deep venous drainage & $45(20 \%)$ & $32(24 \%)$ & $13(15 \%)$ & .126 \\
\hline Venous ectasia & $54(24 \%)$ & $27(20 \%)$ & $27(31 \%)$ & .061 \\
\hline Arterial aneurysm & $20(9 \%)$ & $14(10 \%)$ & $6(7 \%)$ & .475 \\
\hline Intranidal aneurysm & $42(19 \%)$ & $33(24 \%)$ & $9(10 \%)$ & .020 \\
\hline Mean No. of procedures & $1.6 \pm 0.9$ & $1.4 \pm 0.8$ & $1.8 \pm 1.1$ & .003 \\
\hline $\begin{array}{l}\text { Duration of follow-up } \\
\text { angiography (mo) }\end{array}$ & $9.7 \pm 11.9$ & $8.7 \pm 10.4$ & $11.3 \pm 13.8$ & .117 \\
\hline Angiographic result & & & & .091 \\
\hline Complete exclusion & $205(92 \%)$ & $128(94 \%)$ & $77(88 \%)$ & \\
\hline Remnant & $19(8 \%)$ & $8(6 \%)$ & $11(12 \%)$ & 1.000 \\
\hline Post-EVT AVM surgery & $7(3 \%)$ & $4(3 \%)$ & $3(4 \%)$ & NA \\
\hline Post-EVT radiosurgery & $8(4 \%)$ & $2(2 \%)$ & $6(8 \%)$ & NA \\
\hline Severe post-EVT hematoma & $11(5 \%)$ & $7(5 \%)$ & $4(5 \%)$ & 1.000 \\
\hline Significant post-EVT ischemia & $5(2 \%)$ & $4(3 \%)$ & $1(1 \%)$ & .651 \\
\hline Postop outcome (mRS) & & & & .001 \\
\hline Good (0-2) & $179(80 \%)$ & $96(71 \%)$ & $83(94 \%)$ & \\
\hline Poor $(3-5)$ & 44 (19\%) & $40(29 \%)$ & $4(5 \%)$ & \\
\hline Mortality (6) & $1(0.4 \%)$ & $0(0 \%)$ & $1(1 \%)$ & \\
\hline $\begin{array}{l}\text { Improved/unchanged } \\
\text { mRS score }\end{array}$ & $211(94 \%)$ & $127(93 \%)$ & $85(96 \%)$ & 1.000 \\
\hline
\end{tabular}

Note:-NA indicates not applicable; postop, postoperative.

${ }^{a}$ Data are presented as No. (\%) or means.

Table 2: Cure rate according to location of AVM $^{\mathrm{a}}$

\begin{tabular}{lcccc}
\hline & Total & $\begin{array}{c}\text { Complete } \\
\text { Exclusion }\end{array}$ & Remnant & $\begin{array}{c}P \\
\text { Value }^{\mathrm{b}}\end{array}$ \\
\hline $\begin{array}{l}\text { Location } \\
\text { Cortical and } \\
\quad \text { subcortical }\end{array}$ & $176(100 \%)$ & $159(90.3 \%)$ & $17(9.7 \%)$ & .338 \\
Deep & $19(100 \%)$ & $19(100 \%)$ & $0(0 \%)$ & \\
Infratentorial & $29(100 \%)$ & $27(93.1 \%)$ & $2(6.9 \%)$ & \\
Eloquent & $77(100 \%)$ & $76(98.7 \%)$ & $1(1.3 \%)$ & .004 \\
Noneloquent & $147(100 \%)$ & $129(87.8 \%)$ & $18(12.2 \%)$ & \\
\hline
\end{tabular}

${ }^{a}$ Data are presented as No. (\%)

${ }^{\mathrm{b}}$ Fisher exact test.

\section{Predictive Variables of Clinical Outcome}

Univariate analysis showed that factors associated with poor outcome were hemorrhagic history $(P=.000)$, preoperative condition (mRS $0-1$ versus mRS 2-5) $(P=.000)$, eloquent location of the $\operatorname{AVM}(P=.008)$, and infratentorial location of the $\operatorname{AVM}(P=.010)$. In contrast, no association was found with age, sex, Spetzler-Martin grade, lateralization of the AVM, presence of deep drainage, presence of an intranidal aneurysm, number of procedures, volume of Onyx, use of $n$-butyl2-cyanoacrylate, and the number of embolized pedicles.

A multivariate analysis was performed, including the 4 factors associated with poor outcome in univariate analysis, which were entered into the model. In this analysis, only the preoperative condition (poor preoperative mRS score) was associated with poor outcome (OR $=0.029, P=.000)$. The hemorrhagic history of the AVM, eloquent location of the AVM, infratentorial location of the AVM, and supplementary grade $\leq 3$ were not found to be predictive factors of poor outcome.

\section{DISCUSSION}

This study represents the results of endovascular management as the first-line treatment approach for low-grade BAVMs in a single high-volume center: Ninetytwo percent of BAVMs were completely obliterated by an endovascular approach alone $(62.1 \%$ of those in 1 single EVT session), with a permanent neurologic deficit of $5 \%$ and a $0.4 \%$ mortality rate. According to their size, low-grade BAVMs were reported to be suitable for complete exclusion by only a single session. ${ }^{5-8}$ The development of new tools allows supraselective catheterization of the nidus with prolonged embolization resulting in better exclusion of the nidus and draining veins. ${ }^{9,10}$

The deeply located, the infratentorial, and eloquently located BAVMs were reported to be associated with higher rates of treatment failure and complications. ${ }^{7}$ Nevertheless, in our experience, the cure rate in those locations is as high as that in the cortical location with a similar complication rate.

The treatment of unruptured BAVMs remains controversial, even more so since the publication of the ARUBA trial ${ }^{2}$ and the Scottish Intracranial Vascular Malformation Study. ${ }^{11}$ Nevertheless, our study shows encouraging results of EVT for low-grade unruptured BAVMs, with $88 \%$ complete exclusion and $6 \%$ poor outcome, which need to be confirmed in randomized trials with a comparative group undergoing conservative management.

In the literature search we performed, overall cure rates of AVM EVT ranged from $23.5 \%$ to $94 \% .^{1,7,12-20}$ When low-grade AVMs were extracted from the studies, the cure rate was about $93 \%$. In a review of 439 low-grade AVMs treated solely by EVT, the complication rate was about $4.1 \%$ and the mortality was about $0.5 \%$ (Table 3 ).

Surgery is considered the standard and first-choice treatment for low-grade AVMs, with a mean cure rate of 98\% (94\%-100\%), mean complications of $2.2 \%(0 \%-6 \%)$, and mortality rate of $0 \%-$ 
Table 3: Summary of endovascular treatment for low-grade brain arteriovenous malformations $^{\mathrm{a}}$

\begin{tabular}{lcccc}
\hline \multicolumn{1}{c}{ Author, Year } & $\begin{array}{c}\text { No. of } \\
\text { Patients }\end{array}$ & Morbidity & Mortality & $\begin{array}{c}\text { Cure } \\
\text { Rate }\end{array}$ \\
\hline Maimon et al, 2010 & 8 & $0(0 \%)$ & $0(0 \%)$ & $5(63 \%)$ \\
van Rooji WJ et al, & 20 & $0(0 \%)$ & $0(0 \%)$ & $19(96 \%)$ \\
$\quad 2012^{7}$ & & & & \\
Xu et al, 20119 $^{19}$ & 16 & $1(6.3 \%)$ & $0(0 \%)$ & $9(56 \%)$ \\
Saatci et al, 2011 & 158 & $4(2.5 \%)$ & $1(0.6 \%)$ & $155(98 \%)$ \\
Abud et al, 2011' & 8 & $1(12.5 \%)$ & $0(0 \%)$ & $8(100 \%)$ \\
Durst et al, 2015 & 5 & $\mathrm{NA}$ & $0(0 \%)$ & $5(100 \%)$ \\
Our study, 2018 & 224 & $12(5.4 \%)$ & $1(0.4 \%)$ & $206(92 \%)$ \\
Total & 439 & $18(4.1 \%)$ & $2(0.5 \%)$ & $407(93 \%)$ \\
\hline
\end{tabular}

Note:-NA indicates not applicable.

${ }^{a}$ Data are presented as No. (\%).

2\%. ${ }^{1,4,21-28}$ However, the deep and eloquently located AVMs can be inaccessible or at high risk for surgery. ${ }^{2,24,29,30}$ Although $8 \%-$ $45 \%$ of low-grade AVMs benefit from preoperative embolization that results in easier AVM surgery with fewer complications, ${ }^{2,23,24,31}$ only $7.5 \%$ of our patients required surgery or radiosurgery for completing exclusion of the AVM. Cosmetic problems are another issue for brain surgery, which is not the case in endovascular treatments.

The eloquently located AVMs are associated with a higher risk of neurologic complications $(4 \%-10 \%))^{1,23,24,32}$ Use of functional MR imaging before an operation does not seem to reduce the neurologic complication rate following the operation. ${ }^{32}$ The complete resection of deeply located AVMs is less frequent with higher morbidity of $0 \%-13 \%$ and higher mortality of $0 \%-$ $6 \% .{ }^{27,30,31,33-36}$ The deeply located AVMs also benefit from preoperative embolization in up to $54 \%$ of cases, more than the superficial ones. ${ }^{31,35}$ The diffuse architecture of AVMs is also an important limitation for surgery. ${ }^{1}$ Supplementary grading, patient age, architecture of AVMs, and location of AVMs are shown to be important preoperative factors for correct stratification of patients for an operation to increase the rate of complete resection and reduce the risk of complications. ${ }^{1}$

Radiosurgery is considered an effective alternative approach to surgery for small AVMs, especially those located in deep or eloquent areas. Yet, the 2- to 3-year delayed response puts patients at risk of hemorrhage, particularly in ruptured cases, and it even seems not to be limited to 3 years but could be up to 8 years after AVM obliteration. ${ }^{37,38}$ The cure rate of radiosurgery is about 70\%-93\% for low-grade AVMs, with permanent symptomatic complications of $3 \%-12 \%$, rebleeding of $1.7 \%-10 \%$, and mortality of $0 \%-3 \% .^{1,39-46}$ In a recent multicentric study of 2236 patients treated by gamma knife, ${ }^{46}$ complications, including symptomatic and permanent radiation-induced changes, were reported in $9 \%$ and $3 \%$, respectively, and the risk of postradiation hemorrhage was $1.1 \%$ annually and $9 \%$ in total for patients with a history of hemorrhage and $6 \%$ for those without a history of hemorrhage. The risk of hemorrhage increases with increasing age, deeply located AVMs, and increasing prescription isodose volume. ${ }^{38}$ The radiation-induced complications occurred at intervals of 6-18 months, and the most important risk factors were radiation dose and location of the AVM. ${ }^{46,47}$ Brain stem and deep location such as the thalamus were reported to have about 4 and 2 times more irreversible symptomatic adverse radiation reaction (11\% and $7 \%)$ than other locations, respectively. ${ }^{47}$

\section{Limitations}

Our study presents several limitations. There are inherent selection biases due to the observational design of this work. Notably, about $20 \%$ of patients were not included in the study because their treatment was still ongoing, and the outcomes of these patients might modify our results. The monocentric nature of the study could also affect the results. No treatment from this series was performed through a venous approach (an alternative endovascular approach that has recently gained wider acceptance); our study thus does not have insight into this technique. Other interesting anatomic features (such as number of feeders) were not prospectively collected.

Further multicenter studies, with different treatment modalities such as an operation, EVT, and radiosurgery, may better clarify the different aspects in the management of low-grade AVMs. More randomized trials are also necessary to confirm the benefits of curative treatment for unruptured BAVMs because current evidence is in favor of conservative management.

\section{CONCLUSIONS}

The results of our study show a high rate of complete exclusion by EVT for low-grade AVMs with a low complication rate (5\%). Accordingly, EVT may be effective and safe for treatment of lowgrade BAVMs, especially in deep and eloquent locations where an operation has many limitations.

\section{REFERENCES}

1. Potts MB, Lau D, Abla AA, et al. Current surgical results with lowgrade brain arteriovenous malformations. J Neurosurg 2015;122: 912-20 CrossRef Medline

2. Mohr JP, Parides MK, Stapf C, et al; international ARUBA investigators. Medical management with or without interventional therapy for unruptured brain arteriovenous malformations (ARUBA): a multicentre, non-blinded, randomised trial. Lancet 2014;383: 614-21 CrossRef Medline

3. Magro E, Gentric JC, Darsaut TE, et al. Responses to ARUBA: a systematic review and critical analysis for the design of future arteriovenous malformation trials. J Neurosurg 2017;126:486-94 CrossRef Medline

4. Spetzler RF, Martin NA. A proposed grading system for arteriovenous malformations. J Neurosurg 1986;65:476-83 CrossRef Medline

5. Crowley RW, Ducruet AF, McDougall CG, et al. Endovascular advances for brain arteriovenous malformations. Neurosurgery 2014; 74(Suppl 1):S74-82 CrossRef Medline

6. Möhlenbruch M, Bendszus M, Rohde S. Comment on: curative embolization of brain arteriovenous malformations with Onyx-patient selection, embolization technique, and results. Clin Neuroradiol 2012;22:181-82 CrossRef Medline

7. van Rooij WJ, Jacobs S, Sluzewski M, et al. Curative embolization of brain arteriovenous malformations with Onyx: patient selection, embolization technique, and results. AJNR Am J Neuroradiol 2012; 33:1299-304 CrossRef Medline

8. van Rooij WJ, Sluzewski M, Beute GN. Brain AVM embolization with Onyx. AJNR Am J Neuroradiol 2007;28:172-77; discussion 178 Medline

9. Herial NA, Khan AA, Sherr GT, et al. Detachable-tip microcatheters for liquid embolization of brain arteriovenous malformations and fistulas: a United States single-center experience. Neurosurgery 2015;11(Suppl 3):404-11; discussion 411 CrossRef Medline

10. Maimon S, Strauss I, Frolov V, et al. Brain arteriovenous malformation treatment using a combination of Onyx and a new detachable tip microcatheter, SONIC: short-term results. AJNR Am J Neuroradiol 2010;31:947-54 CrossRef Medline

AJNR Am J Neuroradiol 40:668-72 Apr 2019 www.ajnr.org 671 
11. Al-Shahi Salman R, White PM, Counsell CE, et al; Scottish Audit of Intracranial Vascular Malformations Collaborators. Outcome after conservative management or intervention for unruptured brain arteriovenous malformations. JAMA 2014;311:1661-69 CrossRef Medline

12. Abud DG, Riva R, Nakiri GS, et al. Treatment of brain arteriovenous malformations by double arterial catheterization with simultaneous injection of Onyx: retrospective series of 17 patients. AJNR Am J Neuroradiol 2011;32:152-58 CrossRef Medline

13. Baharvahdat $\mathrm{H}$, Blanc R, Termechi R, et al. Hemorrhagic complications after endovascular treatment of cerebral arteriovenous malformations. AJNR Am J Neuroradiol 2014;35:978-83 CrossRef Medline

14. Elsenousi A, Aletich VA, Alaraj A. Neurological outcomes and cure rates of embolization of brain arteriovenous malformations with n-butyl cyanoacrylate or Onyx: a meta-analysis. J Neurointerv Surg 2016;8:265-72 CrossRef Medline

15. Katsaridis V, Papagiannaki C, Aimar E. Curative embolization of cerebral arteriovenous malformations (AVMs) with Onyx in 101 patients. Neuroradiology 2008;50:589-97 CrossRef Medline

16. Mounayer C, Hammami N, Piotin M, et al. Nidal embolization of brain arteriovenous malformations using Onyx in 94 patients. AJNR Am J Neuroradiol 2007;28:518-23 Medline

17. Pierot L, Cognard C, Herbreteau D, et al. Endovascular treatment of brain arteriovenous malformations using a liquid embolic agent: results of a prospective, multicentre study (BRAVO). Eur Radiol 2013;23:2838-45 CrossRef Medline

18. Saatci I, Geyik S, Yavuz K, et al. Endovascular treatment of brain arteriovenous malformations with prolonged intranidal Onyx injection technique: long-term results in 350 consecutive patients with completed endovascular treatment course. J Neurosurg 2011; 115:78-88 CrossRef Medline

19. Xu F, Ni W, Liao Y, et al. Onyx embolization for the treatment of brain arteriovenous malformations. Acta Neurochir (Wien) 2011; 153:869-78 CrossRef Medline

20. Durst CR, Starke RM, Gaughen J, et al. A method for complete angiographic obliteration of a brain arteriovenous malformation in a single session through a single pedicle. J Clin Neurosci 2015;22: 391-95 CrossRef Medline

21. Hamilton MG, Spetzler RF. The prospective application of a grading system for arteriovenous malformations. Neurosurgery 1994;34: 2-6; discussion 6-7 Medline

22. Heros RC, Korosue K, Diebold PM. Surgical excision of cerebral arteriovenous malformations: late results. Neurosurgery 1990;26: 570-77; discussion 577-78 CrossRef Medline

23. Javadpour M, Al-Mahfoudh R, Mitchell PS, et al. Outcome of microsurgical excision of unruptured brain arteriovenous malformations in ARUBA-eligible patients. Br J Neurosurg 2016;30:619-22 CrossRef Medline

24. Morgan MK, Rochford AM, Tsahtsarlis A, et al. Surgical risks associated with the management of grade I and II brain arteriovenous malformations. Neurosurgery 2007;61(1 Suppl):417-22; discussion 422-24 CrossRef Medline

25. Pikus HJ, Beach ML, Harbaugh RE. Microsurgical treatment of arteriovenous malformations: analysis and comparison with stereotactic radiosurgery. J Neurosurg 1998;88:641-46 CrossRef Medline

26. Schaller C, Schramm J. Microsurgical results for small arteriovenous malformations accessible for radiosurgical or embolization treatment. Neurosurgery 1997;40:664-72; discussion 672-74 CrossRef Medline

27. Sisti MB, Kader A, Stein BM. Microsurgery for $\mathbf{6 7}$ intracranial arteriovenous malformations less than $\mathbf{3} \mathrm{cm}$ in diameter. J Neurosurg 1993;79:653-60 CrossRef Medline

28. Sundt TM Jr, Piepgras DG, Stevens LN. Surgery for supratentorial arteriovenous malformations. Clin Neurosurg 1991;37:49115 Medline

29. Davidson AS, Morgan MK. How safe is arteriovenous malformation surgery? A prospective, observational study of surgery as first-line treatment for brain arteriovenous malformations. Neurosurgery 2010;66:498-504; discussion 504-05 CrossRef Medline

30. Gross BA, Duckworth EA, Getch CC, et al. Challenging traditional beliefs: microsurgery for arteriovenous malformations of the basal ganglia and thalamus. Neurosurgery 2008;63:393-410; discussion 410-11 CrossRef Medline

31. Lawton MT, Hamilton MG, Spetzler RF. Multimodality treatment of deep arteriovenous malformations: thalamus, basal ganglia, and brain stem. Neurosurgery 1995;37:29-35; discussion 35-36 CrossRef Medline

32. Lin F, Jiao $\mathrm{Y}, \mathrm{Wu}$ J, et al. Effect of functional MRI-guided navigation on surgical outcomes: a prospective controlled trial in patients with arteriovenous malformations. J Neurosurg 2017;126:1863-72 CrossRef Medline

33. Johnston JL, Johnston IH. The surgical treatment of small deep intracranial arteriovenous malformations: a report of $\mathbf{8 5}$ cases. J Clin Neurosci 1996;3:338-45 CrossRef Medline

34. Liu KD, Lee LS. Microsurgical treatment of deep arteriovenous malformations-basal ganglia and thalamus. Zhonghua Yi Xue Za Zhi (Taipei) 2001;64:23-30 Medline

35. Potts MB, Jahangiri A, Jen M, et al; UCSF Brain AVM Study Project. Deep arteriovenous malformations in the basal ganglia, thalamus, and insula: multimodality management, patient selection, and results. World Neurosurg 2014;82:386-94 CrossRef Medline

36. U HS, Kerber CW, Todd MM. Multimodality treatment of deep periventricular cerebral arteriovenous malformations. Surg Neurol 1992;38:192-203 CrossRef Medline

37. Arslan I, Tezcanli E, Yilmaz M, et al. Gamma knife radiosurgery for arteriovenous malformations: clinical series of 199 patients. Turk Neurosurg 2017;27:301-08 CrossRef Medline

38. Pollock BE, Link MJ, Stafford SL, et al. Stereotactic radiosurgery for arteriovenous malformations: the effect of treatment period on patient outcomes. Neurosurgery 2016;78:499-509 CrossRef Medline

39. Bin Rosli FJ, Mohammed Haspani MS, Izaini Ab Ghani AR. Comparing monomodality treatments of low-grade intracranial arteriovenous malformation at Hospital Kuala Lumpur between 2008 and 2011: a retrospective study. Asian J Neurosurg 2016;11:22-28 CrossRef Medline

40. Boström JP, Bruckermann R, Pintea B, et al. Treatment of cerebral arteriovenous malformations with radiosurgery or hypofractionated stereotactic radiotherapy in a consecutive pooled linear accelerator series. World Neurosurg 2016;94:328 -38 CrossRef Medline

41. Ding D, Yen CP, Xu Z, et al. Radiosurgery for low-grade intracranial arteriovenous malformations. J Neurosurg 2014;121:457-67 CrossRef Medline

42. Friedman WA, Bova FJ, Bollampally S, et al. Analysis of factors predictive of success or complications in arteriovenous malformation radiosurgery. Neurosurgery 2003;52:296-307; discussion 307-08 CrossRef Medline

43. Kano H, Kondziolka D, Flickinger JC, et al. Stereotactic radiosurgery for arteriovenous malformations after embolization: a case-control study. J Neurosurg 2012;117:265-75 CrossRef Medline

44. Koltz MT, Polifka AJ, Saltos A, et al. Long-term outcome of gamma knife stereotactic radiosurgery for arteriovenous malformations graded by the Spetzler-Martin classification. J Neurosurg 2013;118: 74-83 CrossRef Medline

45. Pollock BE, Lunsford LD, Kondziolka D, et al. Patient outcomes after stereotactic radiosurgery for "operable" arteriovenous malformations. Neurosurgery 1994;35:1-7; discussion 7-8 CrossRef Medline

46. Starke RM, Kano H, Ding D, et al. Stereotactic radiosurgery for cerebral arteriovenous malformations: evaluation of long-term outcomes in a multicenter cohort. J Neurosurg 2017;126:36-44 CrossRef Medline

47. Kano H, Flickinger JC, Tonetti D, et al. Estimating the risks of adverse radiation effects after gamma knife radiosurgery for arteriovenous malformations. Stroke 2017;48:84-90 CrossRef Medline 